\title{
Organizational Honestly Guidance by Ability Superintendents
}

\author{
Dr. Nasser Fegh-hi Farahmand ${ }^{1}$
}

\begin{abstract}
The role of organizational is to implement organizational tactic. Effective organizational honestly guidance is one of the important factors in organizations success. There are ability superintendents who argue that formal written planning may be inappropriate for the organizations but this seems a minority view. The tactics importance of organizational customers is discussed as an asset. Also this paper describes the approach to organizational honestly guidance at organizations. This paper proposes a relation of organizational honestly guidance by ability superintendents and reviews the organizational tactics and performance measurement literature to develop a conceptual model and research propositions. It is concluded that ability manager's characteristics can be important in explaining and compilation the organizational honestly guidance within the organizations for implementation. This paper is to explore the ways in which certain characteristics of ability superintendents of organizations generate a tendency to prepare formal written organizational tactics. The ability manager's characteristics showing a significant association with a commitment to organizational honestly guidance and also organizational honestly guidance showed a positive association with those ability superintendents with a growth orientation. In fact, organizations influence whether or not those organizations engage in organizational tactics. In this field, the focus is on the special characteristics of ability superintendents such as education type and level.
\end{abstract}

Key words: organizational honestly guidance, ability superintendents, organizational tactics

\section{Introduction}

The tactic implementation, tactic control, organizational and successful measurement literature develop a conceptual model and research propositions. In fact, without organizational customers organizations would not exist. In order to achieve organizational success, it is important to understand the honestly between

${ }^{1}$ Department of Industrial Management, Tabriz Branch, Islamic Azad University, Tabriz, Iran E-mail:farahmand@iaut.ac.ir 
Organizational honestly guidance by educated Superintendents and tactic deployment success. As guidance itself becomes more emphatically fast-paced and intuitive, in order to deal with complexity and unpredictability, research is beginning to accumulate showing that coaching formats used in guidance support are more effective than training in the older logical comprehensive pursuits. A positive experience throughout the customer's cycle should foster trust and develop loyalty, therefore allowing organizations to generate more revenue for less incremental expenditure. Making new customers aware of a product or service with loyal customers tend to receive more frequently and happy existing customers are more willing to receive other services from organization and try new service offerings. The cost of servicing existing customers can be lower by security of future revenues, which is much higher with happy customers. For tactic purposes, satisfy of an intangible asset in its own right is not particularly relevant; however, an understanding of how this satisfy is comprised and the key metrics that impact on the assets' contribution to organization successful can be extremely beneficial for guidance decision making. Recent research into tactic implementation is damning in its findings. The organizations field is now giving high priority to developing metrics.

The role of organizations is to implement tactic. A fundamental proposition in tactic is that distribution methods must be aligned with customers and competitive advantage. Unfortunately, method successful measurement literature has provided ambiguous guidance to superintendents.

In order to achieve organizational success, it is important to understand the honestly between method successful measures and tactic implementation success. It is also important to know whether, regardless of tactic, the same method successful measures should be used.

The key question in terms of ensuring that method tactic supports organizational successful is how do we know our method tactic is performing? In order to understand whether the method is performing or not, we need to ensure that the method measures are appropriate for each organizational tactic. Although organizational honestly guidance has been one of the fastest growing organizations, critics point to the high failure rate of the organizational honestly guidance projects as evidenced by organizations studies. However, the organizational tactics may serve as a tactic planning document for the superintendents, entrepreneurs and educated workers, a plan to guide the organizational and serve as a basis for taking tactic decisions and also it may serve as a subsequent monitoring device (Deakins, 2003, 329; Feghhi farahmand, 2005, 118). In view of its perceived ongoing value to the small business it might be expected that organizational honestly guidance would be a feature of many, if not most, organizations. 
The purpose of the study is to investigate success and failures of organizational honestly guidance system implementations. Also this study found that the scope, size, complexity and duration of the organizational honestly guidance projects seem to vary quite significantly across organizations. Poor planning, lack of clear objectives and not recognizing the need for organization change are the key reasons for organizational honestly guidance failures. The organizational field is now giving high priority to developing organizational metrics. The role of organizational is to implement organizational tactic. Effective organizational honestly guidance is one of the important factors in organizations success. There are ability superintendents who argue that formal written planning may be inappropriate for the organizations but this seems a minority view. It can be argued that organizational honestly guidance is as important to organizations as to larger organizations and standard textbooks on entrepreneurship offer chapters on organizational plan whilst a range of specialist publications outline the best ways of writing organizational plan (Sahlman, 1997, 67; Monks, 2001, 41; Naffziger, et al, 1991, 21). A fundamental proposition in organizational tactic is that organizational plan must be aligned with customers and competitive advantage. Unfortunately, organizational plan performance measurement literature has provided ambiguous guidance to organizational superintendents. In organizations, where a organizational tactic exists, the preparation of the organizational honestly guidance may have been driven by external forces. The most obvious of these are the requirements of external agencies providing funding for either start up or expansion.

\section{Organizational tactics}

The organizational honestly model suggests tactic is a more important influence on method measures than variables such as organizational honestly characteristics, stage of service lifecycle, market share, organizational or tactic organization unit size, profitability and growth, environment or competitors. Table 1 shows the proposed honestly between method measures for each tactic type.

Control by successful large pull involved frequent successful reporting. Pull organizational would be expected to be similar to cost leaders as they operate in relatively certain environments with existing service receivers and undertake little service innovation. As a result, the measures they use could be frequent yet still be meaningful. Organizational honestly guidance were outcome focused and neither multidimensional nor tactic. The control method of successful pull included careful output monitoring and was expected to be associated with pull.

Based on the degree of service innovation inherent in pull tactics, it is likely that they would compete with higher quality services and be first to market with new 
generation services. Conversely, pull would depend more on efficiency and cost reduction to compete and rely more on older generation services. As a result, pull would place greater emphasis on cost control measures in supporting organizations tactic. Successful measures must be aligned with organization tactic. The optimum control system required two different approaches operating at different hierarchal levels. Like all scientific enterprises, a period of accumulation of evidence will be required before definitive conclusions may be drawn (Deakin, et al 2003, 64; Mason, et al, 2004, 3).

Table 1: organizations tactic types

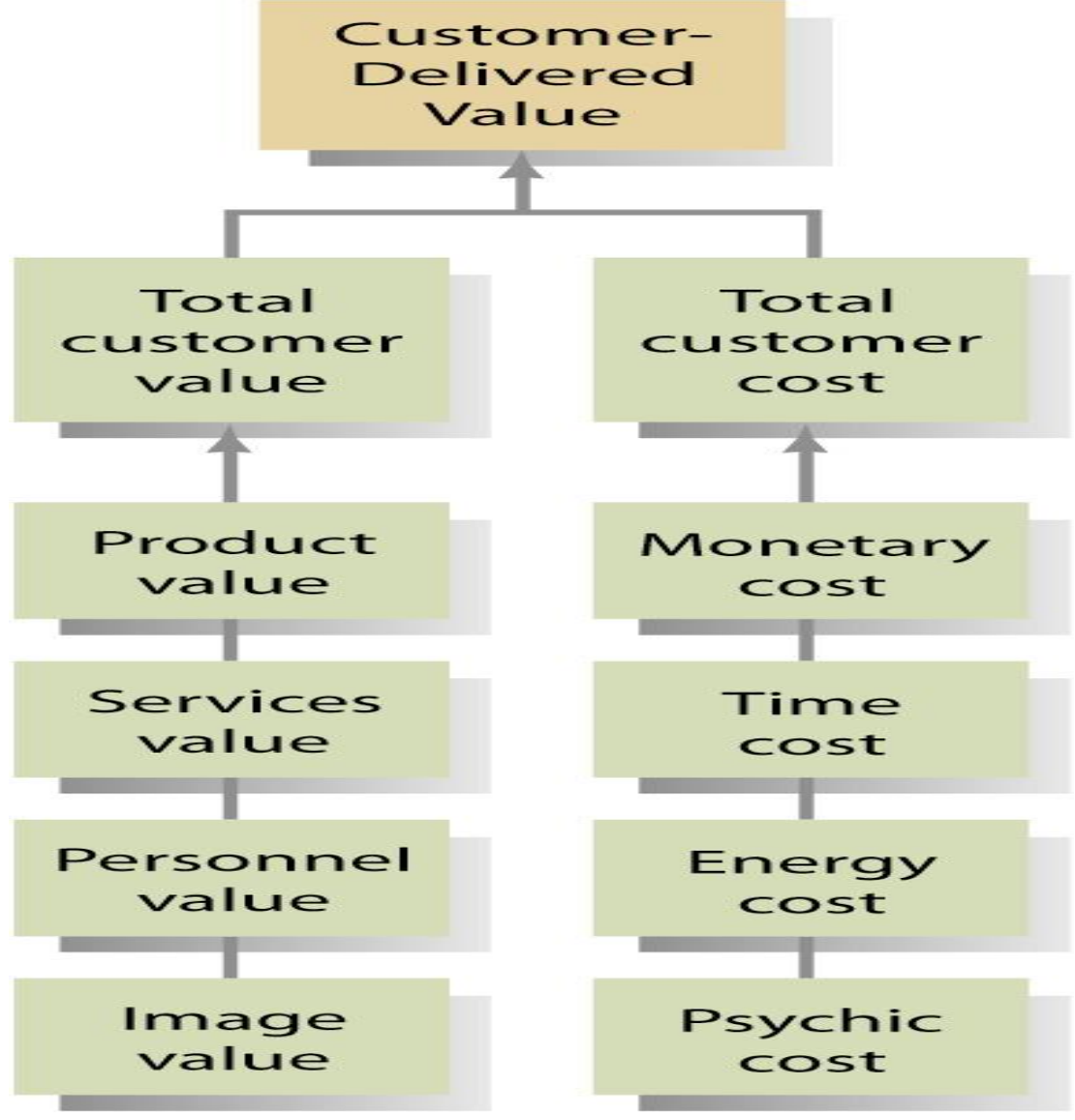

Ability superintendents' recent research reviewing corporate coaching programs that we can see this move from intuition towards rationalized models as complementary and off-setting to developments in tactic guidance (Mintzberg, 1994, 89; Mintzberg, et al, 1998, 45; Schwenk, et al, 1993, 17). However, there are early gleanings that evidence based evaluation research is underway. For this reason by coupling quality with customer service recovering satisfaction as Figure 1, a few tactical actions for implementation (Mason and Stark, 2004, 205; Peters, 1988, 160) can make the challenge simpler and provide leadership (Minnow, 1996, 
5; Feghhi farahmand, 2009; Rue \& et al, 1998, 97). To assist in understanding the process used in a certain application; avoid potential misconceptions regarding the intent and define the activities associated with specific value studies, reclamation has defined four distinct types of value studies.

Figure 1: organizational tactics model

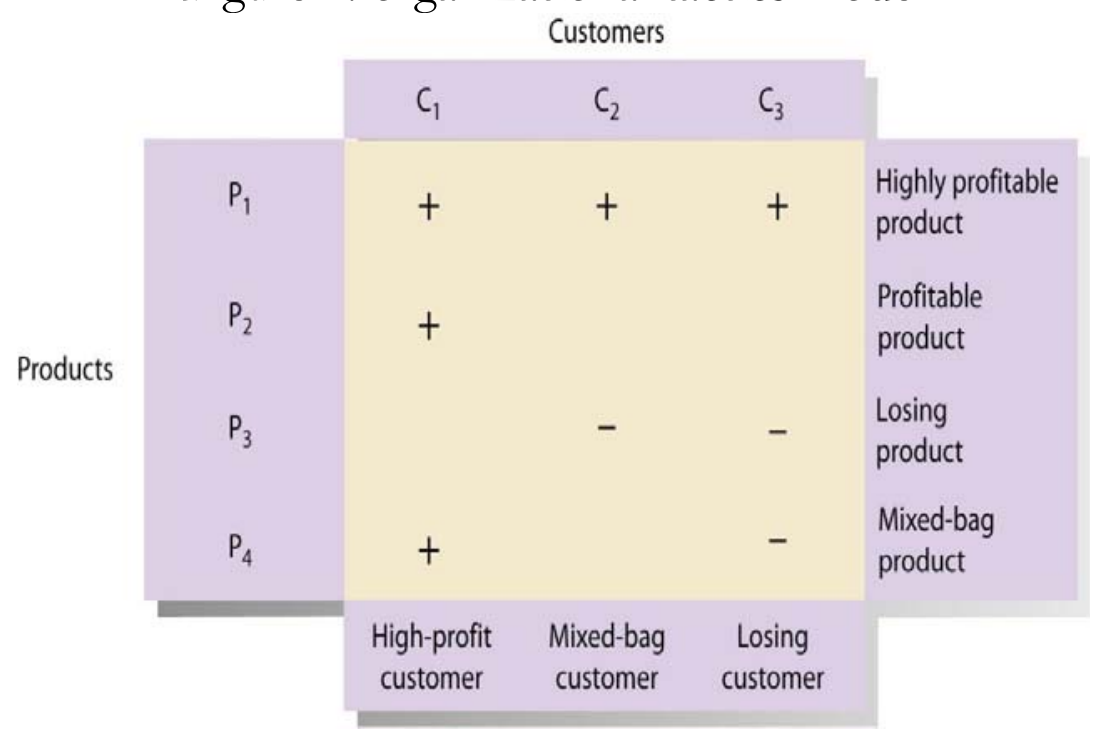

The literature argues shows that the extent to which each determinant of performance impacts firm performance is a function of the performance metrics. Further, define performance as the sum of all processes that will lead superintendents to taking appropriate actions in the present that will create a performing organization in the future or in other words, doing today what will lead to measured value outcomes tomorrow. Also the value chain is a tool to identify key activities that create value $\&$ costs in organizational and identify ways to create more customer value. Therefore organizational capability relies in particular on coaching guidance skills, which rely on emotional intelligence and emphasis oneto-one, dialoguing, subordinate empowerment and mutually agreed targeting. In relation of value core competencies including outsource less critical resources if better quality or cost and own competencies - core business, three characteristics are competitive advantage, applications - many markets and difficult to imitate. Value proposition, and Value network recovering satisfaction are as follows (Curran, et al, 1994; Feghhi farahmand, 2004, 358; Feghhi farahmand, 2005, 187; Nayak, et al, 1994, 47; North, et al, 1997, 187):

- An organization's total quality efforts must begin at the very top and begin with the board of directors (Olivero, et al, 1997, 68; Senge, 1990, 196; Perry, 2001, 66). - An action plan based on the survey feedback should then be formulated by the top guidance and communicated at every board meeting. 
- Develop a vision the organization does not have one already. The key to the initial adoption of quality is continuous communication of the vision within a comprehensive communication plan.

- Senior superintendents need coaching as the new theorists in coaching argue; coaching empowers individuals to achieve their inherent potential.

- Employees, shareholders and customers, suppliers and competitors have a stake and essential ingredient for success is senior quality circles, which provides leadership in quality and stimulates cultural change.

- The responsibilities accept of a senior quality committee can include (Feghhi farahmand, 2004, 398): establishing tactic quality goals, allocating resources, sanctioning quality improvement teams, reviewing key indicators of quality, estimating the cost of poor quality, ensuring adequate training of employees and recognizing and rewarding individual and team efforts. For this reason three key questions as value exploration for new opportunities, value creation for new offerings and value delivery for deliver more efficiently is necessary in according Figure 2 as a holistic organizational network:

Figure 2: A holistic organizational network

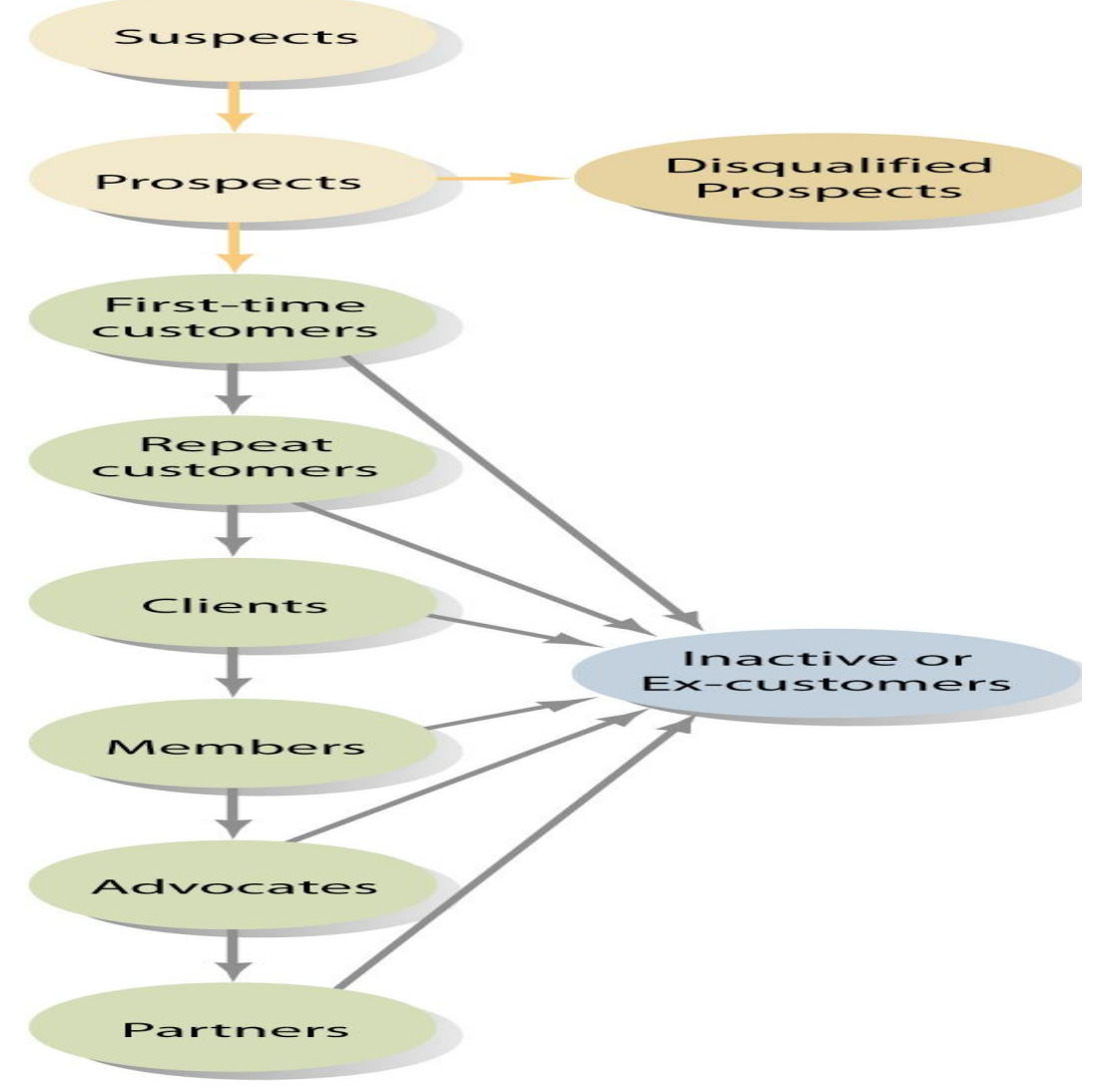

In any case, the level of uncertainty is continuing to increase even as consumer prosperity overlaps into the new century, reacting against the undoubted brilliance 
of the recent industrial era. However, the mainly qualitative evidence available to date suggests that SP within organizations is an activity of a minority (Feghhi farahmand, 2002, 254). There may be a number of reasons for the lack of SP. Historically the typical ability superintendents has tended not to have pursued higher levels of education level or to take formal organizational training. Hence there are two possible reasons why ability superintendents tend not to plan (Chell, 1991, et al, 167) that they are emotionally unsuited to it. Anyhow tactical actions steps for coupling quality with customers or customers including three Vs to Organizational: Value segment,

This survey should be sponsored by the top guidance to send a clear message throughout the organization that quality is linked to customer satisfaction and the senior executives should then present the results to all employees that detailed tactics for improving customer satisfaction can be devised and communicated. In hypercompetitive economy more rational buyers many choices, company win by fine tuning value delivery process \& to choose, provide and communicate superior value. To ensure the opportunity to achieve the highest value, value program staff attempt to keep guidance or administration directed mission charges flexible enough to allow innovation. This staff make most of the recommendations for administrative and procurement processes that could benefit from studies (Feghhi farahmand, 2009, 97; Steele, 1997, 28-68; Storey, 1994, 55; Storey \& et al, 1989, 97). Anyhow is the need to develop a means to inform administrative or procurement staff of the available resources and how to obtain assistance. Therefore core product or service quality and customer benefits return as key drivers (Curran, et al, 1994; Feghhi farahmand, 2005, 58).

For this reason, there is a need to re-track fundamental guidance systems. Such concepts as investment valuation, ethical trading, stakeholder consultation, corporate social responsibility, value investment, preoccupy institutional investor communities.

They think and act intuitively and they are simply unaware of the various tools which would enable them to plan systematically. A further constraint, likely to restrict organizational honestly by ability superintendents, is that they may not have sufficient financial information to prepare a formal plan. A lack of formal organizational honestly planning may also relate to the fact that small organizations are just too busy surviving to take time out to plan ahead whilst others might argue the environment (Ledoux, 1993, 215; Ledoux, 1994, 15). A lack of formal organizational honestly among organizations does not necessarily mean that organization is badly managed. It does, however, suggest that ability superintendents miss out on the opportunity to consider the overall direction of the organizational and guidance decisions may be made on the basis of poor 
information (Curran, et al, 1994, 39; Feghhi farahmand, 2009, 102; Stutely, 2002, 43).

The characteristics of the organization and ability superintendents and also organizations tactics hereafter termed organizational honestly, influencing ability manager's behavior which might be used to inform analysis of the determinants of organizational honestly in organizations. Organization characteristics were controlled out of analysis in order to focus our attention on the ability superintendents and organizational honestly variables.

Organizational honestly guidance systems were both outcome focused and financially focused and were neither multidimensional nor tactic. The organizational honestly guidance became broader and included measures of innovation and service receiver satisfaction.

The most essential successful originated tools of organizations are:

- The organizational honestly process guidance model;

- The organizational honestly process auditing and assessment procedure of process successful;

- The organizational honestly project guidance model;

- The organizational honestly benchmarking procedure;

The nature of the ability superintendents is seen as critical in other aspects (Nayak et al, 1994, 425; Fisher, 2002, 89) of the activities of organizations. A selection of the ability superintendents' characteristics is the potential to influence an owner manager's propensity to undertake organizational honestly guidance. Predictions of the direction in which the variables (Feghhi Farahmand, 2002, 345; Smith, 1967, 145) will operate are inevitably problematic as there is little prior work on the determinants of organizational honestly guidance upon which we can draw (Smith, 1967, 25; Curran, et al, 1994; Feghhi farahmand, 2005, 37; Kuratko \& et al, 2004, 64):

1) Organizational honestly ability: This variable has been identified as important in a number of studies.

2) Organizational honestly experience: It may be strongly linked to ability and it could be argued that it might work in two ways. A long number of years running an organization as ability superintendents might increase a propensity to plan future directions for the organizational or indeed, once the initial phases had passed and funding secured planning might well be less of a priority.

3) Organizational honestly education level: In the context of organizational honestly guidance, this variable might seem reasonable to hypothesis that the more highly educated ability superintendents will tend to be more aware of the desirability of organizational honestly guidance and thus, organization run by the better educated ability superintendents might be more likely to have organizational plans. 
4) Organizational honestly innovation: A distinction here may be drawn between those for whom the current organization is their first and serial founders.

5) Organizational honestly organizing: Organization founders are drawn either from operatives or from those with previous managerial experience.

6) Organizational honestly tactic: Here it might be argued that ability superintendents moving into a new sector might be encouraged to plan rather more than those whose businesses were in sectors in which they had considerable prior experience.

7) Organizational honestly potential: This was introduced into the analysis as it might be expected that local ability superintendents, who grew up in the geographical area under study, will tend to be introspective and less receptive to contemporary guidance practice.

The honestly between organizations and their localities have become an important research area and organization with links with local organizational institutions might be more likely to organizational plan. The argument here would be that mixing with local organizational leaders would increase awareness of the value of organizational honestly guidance. Conversely, mixing with other ability superintendents of small organization might re-enforce towards the idea of organizational honestly guidance, especially where organizational honestly guidance was not seen as a key element of organizational activity.

\section{Organizational honestly guidance}

The organizational honestly guidance refers to the internal systematic approach systematically of the organization guidance and leadership to strive for organization successful excellence. The successful organizational honestly guidance referring to all those measures through which one creates and strengthens confidence and trust in outsiders, especially service receivers, towards the organization abilities and service. When the comprehensiveness of the organizational honestly guidance approach is being emphasized one also can use the concept organizational honestly guidance instead of organizational plan. In practice, however, the both mean the same. Organizational honestly guidance system is a technology-based organization guidance tool for developing and leveraging organizational customers' knowledge to maintain, and strengthen profitable honestly with service receivers. Thus, a organizational honestly guidance system is an essential part of a global organizational honestly guidance tactic which emphasis creation of satisfaction through the development of appropriate honestly with key service receivers segments. The underlying premise of organizational honestly guidance is that organizational honestly creates organizational customers knowledge in order to: 
1) Organizational honestly effectively segment organizational customers,

2) Organizational honestly develops and maintains long-term honestly with profitable organizational customers,

3) Organizational honestly determine how to handle unprofitable organizational customers.

Through the creation and better utilization of service receiver knowledge, the service receiver honestly should improve. Successful implementation of organizational honestly guidance program depends upon four critical factors:

- Organizational honestly guidance readiness assessment,

- Organizational honestly guidance change guidance,

- Organizational honestly guidance project guidance,

- Organizational honestly guidance employee engagement.

Ability superintendents ranged in ability from low to high. Clearly, within this group, there is a sub set of growth oriented ability superintendents whose propensity to undertake organizational honestly guidance might be contrasted with those who were content with their current level of organizational. The latter may well belong to that group of ability superintendents often characterized as running lifestyle organization. From this overview of the selected ability superintendents' characteristics and the tactics of the sampled organization, it is now possible to explore the extent to which these differing characteristics and tactics influence whether or not an organization engages in organizational honestly guidance. The capturing the wrong organizational customers information, unclear goals, inappropriate selection and use of technology, inability to integrate people and processes and use of misleading metrics or improper measurement approaches are the major barriers in implementing and managing organizational customers projects. The seven deadly sins for unsatisfactory organizational honestly guidance outcome are:

- Viewing the organizational honestly guidance initiative as a technology initiative;

- Lack of organizational customers vision;

- Insufficient appreciation of organizational customers' lifetime satisfies;

- Inadequate support from top guidance;

- Underestimating the importance of change guidance;

- Failing to re-engineer organization processes;

The aim of organizational honestly guidance approach is to strive for the organization tactic and operational goals. Organizational honestly guidance is based on a special expertise for enhancing effectiveness and efficiency of organization guidance and leadership. Thus genuine realization of the organizational honestly guidance practices takes place in real organization activities both in the organization tactic leadership as well as in the operational realization of the organization services and targets. The broad challenge for organizational 
honestly guidance is to enhance positive substance of organization brand through various means that are consistent both with respect to one another and aligned with the organization tactic course. As a whole the main principles in organizations approach include the following:

- Focus on supporting the organizational honestly guidance tactic goals of the organization;

- Consistency of different organizational honestly measures in order to strengthen one another;

- Alignment of the whole tactically and operationally for centering on the key issues;

- Comprehensiveness and a scope which covers the entire corporation;

- Integrating organizational honestly guidance measures with organization processes.

Systematic approach instead of building separate systems such as quality systems organizational honestly guidance approach is well harmonized with the organization tactics. On that basis also the quality policy was defined. General intention and direction towards organizational honestly guidance is considered by the organizational policy statements. Always act so that the organizational customers what he or she needs and improve activities and their results continually so that they will be better and more effective and efficient of organizational honestly guidance.

The goal of organizational honestly guidance, i.e. organization excellence, is reached through innovative guidance and leadership practices. In order to realize organizational honestly guidance objectives in all parts of the organization and at all levels of organization and guidance, an organization-wide guidance structure, a leadership infrastructure framework has been defined. The framework model was originally created at organizations. This model covers all organization functions in a natural and flexible manner and covers the following four levels of the organization:

1) The organization level: where the general principles, the common insight, goals, shared tools, and practices concerning organizational honestly guidance are created, including how these principles are to be applied in practice on the basis of the organization requirements.

2) The tactic areas and unit's level: where decisions are made by the general manager of the organization unit and the other top organization leaders, and measures undertaken concerning the entire particular organization and especially the future competitiveness of the organization and guidance of the whole organization system are addressed. The organization system is composed of the interrelated operational organization processes. Very often in corporations there are different organization areas that may be at different development stages. All 
these need different tactic organizational honestly guidance approaches but they may operate within one corporate culture.

3) The operational individual organization processes level: where decisions and measures concerning daily guidance are made and undertaken, and services are realized in real time for organizational customers needs.

4) The human and team's level: where the personal contribution of each member of the organization personnel including the top guidance is provided in natural working environments.

In response to this research gap, this paper investigates whether ability superintendents should differ according to organizational tactic. Ability superintendents were asked whether or not they had a formal organizational honestly guidance for their organization and the period of time to which it applied. All these organizations had very different levels of success. Their success was determined mainly by the honestly between the complexity of the system and the speed and phasing of its development and roll out. A organizational honestly guidance system is not just service receiver interface software. Organizations believe that successful measurement frameworks should be multidimensional. Unfortunately, the early attempts at successful measurement frameworks were too financially oriented and did not provide tactic vision. The main focus is on the role of ability superintendents characteristics in influencing the propensity for organizational honestly guidance. The interdisciplinary conceptual model will provide guidance to ability superintendents in developing contextually relevant method measures.

\section{Conclusion}

In order to understand whether the ability superintendents is performing or not, we need to ensure that the ability superintendents is appropriate for each organizational tactic. The model provides ability superintendents with specific benefits such as measures to organizational honestly guidance with tactically aligned framework for clearer logic behind organizational honestly guidance actions.

Successful measure portfolio discriminates between organizational honestly guidance efficiency and effectiveness successful measures in order to avoid suboptimal successful. Set of organizational honestly guidance guidelines to ensure method synergies are achieved in the targeting of high and low organizational customers lifetime satisfy segments with matching method costs and method response to organizational customers satisfy. Many of organizations have sustained their organizational honestly guidance systems focus over time, although these investments may or may not be considered part of a long-term organizational 
honestly guidance tactic. The scope, size, complexity and duration of the organizational honestly guidance projects seem to vary quite significantly across organizations. Poor planning, lack of clear objectives and not recognizing the need for organization change are the key reasons for organizational honestly failures.

The most recent organizational honestly guidance programs, for example some have clearly benefited from previous organizational honestly guidance systems experience of suppliers, including considerably reduced implementation times and lower risk levels for comparable size programs.

Ability superintendents have too many successful measures, and a simplified set with fewer yet more important metrics would lead to superior successful. Successful ability superintendents are hindered by too many low-level measures. Ideal successful ability superintendents must include measures which are tactically relevant as well as measures which address both efficiency and effectiveness of organizational honestly guidance. For ability superintendents, the area of organizational honestly method successful measurement is an area that represents a significant opportunity for organizational honestly guidance investment and organizational plan guidance attention.

\section{Reference}

Burns, P. (2001), Entrepreneurship and small Business. Basingstoke, Palgrave. Pp 34-74.

Chakravarthy, B. S. (1986) 'Measuring tactic successful', Tactic Guidance Journal, Vol. 7, No. 5, pp. 437-458.

Chell, E. (2001), Entrepreneurship: Globalization, Innovation and Development, London, Thomson Learning, p67.

Chell, E. Haworth, J. and Brearley, S. A. (1991), The Entrepreneurial Personality, London, Rutledge, p 167.

Collins, F., Holzmann, O. and Mendoza, R. (1997) 'Tactic, budgeting, and crisis in Latin America', Accounting and Society, Vol. 22, No. 7, pp. 669-689.

Curran, J. and Blackburn, R. (1994), Business planning and Local Economic Networks, London, Paul Chapman, pp 31-49.

Day, G. (2000) 'Capabilities for forging Customer honestlys', Report No. 00-118, Organizational Science Institute, Cambridge, MA.

Deakin, D. \& Freel, M. (2003), Entrepreneurship and Business planning, London, McGraw Hill, pp 302-412.

Dobni, B., Dobni, D. and Luffman, G. (2001) 'Behavioural approaches to organizational tactic implementation', Organizational Intelligence \& Planning, Vol. 19, No. 6, pp. 400-408.

Eccles, R. G. (1991) 'The successful measurement manifesto', Harvard Business Review, Vol. 69, No. 1, pp. 131-137.

Erffmeyer, R. C. and Johnson, D. A. (2001) 'An exploratory study of sales force automation practices: Expectations and realities', Journal of Personal Selling and Sales Guidance, Vol. 21, No. 2, pp. 167-175.

Feghhi Farahmand, Nasser (2001), Executive Guidance Process, Islamic Azad University, Tabriz Branch, Iran, pp 99-113. 
Feghhi Farahmand, Nasser (2003), Permanent Guidance of Organization, First edition, Frouzesh Publication, Tabriz, Iran, pp 70-83.

Feghhi Farahmand, Nasser (2003), Tactic Structure of Organization Guidance Process, Forth edition, Islamic Azad University, Tabriz Branch, Iran, pp 41-125.

Feghhi Farahmand, Nasser (2005), Tactic Guidance of Organization, First edition, Frouzesh Publication, Tabriz, Iran, pp 85-149.

Feghhi Farahmand, Nasser (2009), Organization Tactic Plan compilation, First edition, Frouzesh Publication, Tabriz, Iran, pp 74-314.

Feghhi farahmand, Nasser (2011), Active and Dynamic Guidance of Organization, Second edition, Frouzesh Publication, Tabriz, Iran, pp 87-90.

Feghhi Farahmand, Nasser (2011a), Technology Guidance of Organization, Second edition, Frouzesh Publication, Tabriz, Iran, pp 11-18.

Fiegener, M. K. (1994) 'Matching organization-level tactic controls to tactic: Impact on control system effectiveness', Journal of Applied organization Research, Vol. 10, No. 1, pp. 25-34.

Fisher, A. (2002), Annie weighs in on executive coaching and untruths on resumes, Fortune Magazine, 13 May, o 89.

Franco, M. and Bourne, M. (2003) 'Factors that play a role in 'managing through measures", Guidance Decision, Vol. 41, No. 8, pp. 698-710.

Gifford, D (1997), The value of going green, Harvard Business Review, 75/5.

Goleman, D., Boyatzis, R. \& McKee, A. (2002), The New Leaders, London, Little, Brown, p 78199.

Govindarajan, V. and Fisher, J. (1990) 'Tactic, control systems, and resource sharing: Effects on organization-unit successful', Academy of Guidance Journal, Vol. 33, No. 2, pp. 259-285.

Gresov, C. and Drazin, R. (1997) 'Equifinality: Functional equivalence in organization design', Academy of Guidance Review, Vol. 22, No. 2, pp. 403-428.

Hamel, G. (2001), Leading the Revolution, Boston, Harvard Business School Press, p89.

Henningsen, C (2002), Investing as if the world really mattered, Corporate Environmental Tactic, 9 /2, pp 22-39.

Hunt, S. D. and Lambe, J. (2000) 'Organizational's contributions to organization tactic; Market orientation, honestly organizational, and resource-advantage theory', International Journal of Guidance Reviews, Vol. 2, No. 1, pp. 17-34.

Jain, R., Jain, S. and Dhar, U. (2007) 'CUREL: A scale for measuring service receiver honestly guidance effectiveness in service sector', Journal of Services Research, Vol. 7, No. 1, pp. 37-58.

Jaworski, B. J. and Kohli, A. K. (1991) 'Market orientation', Journal of Organizational, Vol. 57, No. 3 , pp. 53-70.

Jeuland, A. P. and Shugan, S. M. (1983) 'Managing method profits', Organizational Science, Vol. 2, No. 3, pp. 239-272.

Johnson, Steven (2001), The connected lives of ants, brains, cities and software, Penguin, pp 4463.

Journal of Database Organizational \& Customer Tactic Guidance (2008) 15, 68-78. doi:10.1057/dbm.2008.5; published online 9 June 2008

Kale, S. H. (2004) 'SRRM failure and the seven deadly sins', Organizational Guidance, Vol. 13 (September/October), pp. 42-46.

Kaplan, R. S. and Norton, D. P. (1996) 'Using the balanced scorecard as a tactic guidance system', Harvard Business Review, Vol. 74, No. 1, pp. 75-85.

Kirby, D. A. (2003), Entrepreneurship, Maidenhead, McGraw Hill, p 82 
Kumar, K. and Subramanian, R. (1997/1998) 'Porter's tactic types: Differences in internal processes and their impact on successful', Journal of Applied organization Research, Vol. 14, No. 1, pp. 107-124.

Kuratko D F and Hodgetts R M (2004), Entrepreneurship: Theory, Practice Mason, Ohio, Thomson South Western, p64.

Larson, P. D. (1991) 'Product quality, total costs and the integration of the utility-producing functions unpublished $\mathrm{PhD}$ dissertation University of Oklahoma.

Larson, P. D. and Lusch, R. F. (1992) 'Functional integration in organizational methods: A determinant of product quality and total cost', Journal of Organizational Methods, Vol. 2, No. 1, pp. 1-28.

Lassar, W. M. and Kerr, J. L. (1996) 'Tactic and control in supplier-distributor honestlys: An agency perspective', Tactic Guidance Journal, Vol. 17, No. 8, pp. 613-632.

Lebas, M. and Euske, K. (2002) 'Delineation of successful', in: Neely, A. (Ed.) ' Performance measurement: Theory and practice', Cambridge University Press, Cambridge, UK, pp. 65-79.

Ledoux, JE (1993), Emotional memory systems in the brain. Behavior and Brain Research, v 58, p 112-215.

Lewis, M. C. and Lambert, D. M. (1991) 'A model of method member successful, dependence, and satisfaction', Journal of Retailing, Vol. 67, No. 2, pp. 205-225.

Lubieniecki, E. C. and Desrocher, N. J. (2003) 'The case for simple comparison: A simple successful scorecard for effectiveness and efficiency', Journal of Corporate Real Estate, Vol. 6, No. 1, pp. 39-52.

Maselli, J. (2001) 'People problems', InformationWeek, 9 July, pp.35-42.

Mason, C and Stark, M. (2004), What do investors look for Business Plan, International small Business Journal, 22, p3.

McGovern, J., Lindemann, M., Vergara, M., Murphy, S, Barker, MA \& Warrenfeltz, R. (2001), Maximizing the impact of executive coaching: Behavioral change, organisational outcomes, and return on investment. www.mentors.ca/coachingnews.html.

Merlin Stone, 1 Broadmead Close, Hampton, TW12 3RT, UK.

Michael J. Valos, Faculty of organization and Law Bowater School of Guidance \& Organizational Deakin University, 221 Burwood Highway Burwood Vic. 3125 Australia.

Miles, R. E. and Snow, C. C. (1978) 'Organisational tactic, structure, and process', McGraw-Hill, New York.

Minnow, N (1996), Downsizing corporate responsibility. Public Relations Tactic 2, vol. 3, p5. Mintzberg, H. (1994), The rise and fall of Tactic Planning, Prentice Hall International, p81-109. Mintzberg, H., Alstrand, B. \& Lample, J. (1998), Tactic Safari. The Free Press, pp 23-67.

Moedritshcher, G. and Mussnig, W. (2005) 'Evaluating the long term benefit of SRRM-systems: A cost-oriented approach', International Journal of Innovation and Technology Guidance, Vol. 2, No. 4, pp. 367-389.

Naffziger, D. Kuratko, D. (1991), An Investigation into the Planning In small Business, Journal of Business and Entrepreneurship, Fall, p 21.

Najmi, M., Rigas, J. and Fan, I. -S. (2005) 'A framework to review successful measurement systems', organization Process Guidance Journal, Vol. 11, No. 2, pp. 109-122

Nayak, A and Greenfield, S. (1994), The Use Of Guidance Accounting Information, Finance and the organizations, London, Rutledge, p47.

Neely, A. D., Gregory, M. and Platts, K. (2005) 'Successful measurement system design: A literature review and research agenda', International Journal of Operations \& Production Guidance, Vol. 25, No. 12, pp. 1228-1263. 
Noble, C. H. and Mokwa, M. P. (1999) 'Implementing organizational tactics: Developing and testing a managerial theory', Journal of Organizational, Vol. 63, No. 4, pp. 57-73.

North, J., Blackburn, R and Curran, J. (1997), Reaching small Business and Enterprising Futures, London, Paul Chapman.

Olivero, G., Bane, K.D., Kopelman, RE (1997), Executive coaching as a transfer of training tool: Effects on productivity in a public agency. Public Personnel Guidance, 26, 4, p 68.

Paswan, A. K. (2003) 'Method support activities and perceived goal orientation: An exploration in the Indian market', Asia Pacific Journal of Organizational and Logistics, Vol. 15, No. 4, pp. 19-41. Payne, A. and Frow, P. (2006) ' Customer honestly guidance: From tactic to implementation', Journal of Organizational Guidance, Vol. 22, pp. 135-168.

Reinhartz, W., Krafft, M. and Hoyer, W. (2004) 'The service receiver honestly guidance process: Its measurement and impact on successful', Journal of Organizational Research, Vol. 31 (August), pp. 293-305.

Rowley, J. (2002) 'Synergy and tactic in e-organization', Organizational Intelligence \& Planning, Vol. 20, No. 4/5, pp. 215-222.

Rue, L. and Ibrahim, N. (1998), Planning Sophistication and Performance in small Businesses, Journal of small Business Guidance, 36, p 97.

Sahlman, W. A. (1997), How to write a great Business Plan, Harvard Business Review, JulyAugust,pp 61- 98.

Schmitz, J. and Platts, K. W. (2004) 'Supplier logistics successful measurement: Indications from a study of the automotive industry', International Journal of Production Economics, Vol. 89, No. 2, pp. 231-243.

Schwenk, C. R. and Shrader, C. B. (1993), Effects Of Formal Tactic Planning, Entrepreneurship: Theory and Practice, p17.

Senge P, Roberts C and Ross B. Kleiner A (1995): “The Fifth Discipline Fieldbook", Nicholas Brealey Publishing Limited, London

Senge, P. M. (1990) 'The leader's new work. Building learning organizations', Sloan Guidance Review, Vol. 32, pp. 7-24.

Simons, R. (1987) 'Accounting control systems and organization tactic: An empirical analysis', Accounting organizations and Society, Vol. 12, No. 4, pp. 357-374.

Sirivastava, R. K., Shervani, T. A. and Fahey, L. (1999) 'Organizational, organization process, and shareholder satisfy: An organizationally embedded view of organizational activities and the discipline of organizational', Journal of Organizational, Vol. 63, No. 4, pp. 168-179

Slater, S. F. and Narver, J. C. (1995) 'Market orientation and the learning organization', Journal of Organizational, Vol. 59, No. 3, pp. 63-74.

Smith, N. R. (1967), The Entrepreneur and His Organization, University of Michigan: Bureau of Business and Economic Research, pp 112-184.

Speier, C. and Venkatesh, V. (2002) 'The hidden minefields in the adoption of sales force automation technologies', Journal of Organizational, Vol. 66, No. 3, pp. 98-112.

Stacey, R. D. (2000), Tactic Guidance and Organisational Dynamics, Prentice Hall, p 23-42.

Steele, R. S. (1977), Power motivation, activation and inspirational speeches. Journal of Personality, 45, pp 28-68. 